\title{
Risk of placenta previa in second birth after first birth cesarean section: a population-based study and meta-analysis
}

Ipek Gurol-Urganci ${ }^{1,2^{*}}$, David A Cromwell ${ }^{1,2}$, Leroy C Edozien ${ }^{3}$, Gordon CS Smith ${ }^{4}$ Chidimma Onwere $^{2}$, Tahir A Mahmood ${ }^{2}$, Allan Templeton ${ }^{2}$ and Jan $\mathrm{H}$ van der Meulen ${ }^{1}$

\begin{abstract}
Background: Objective: To compare the risk of placenta previa at second birth among women who had a cesarean section (CS) at first birth with women who delivered vaginally.

Methods: Retrospective cohort study of 399,674 women who gave birth to a singleton first and second baby between April 2000 and February 2009 in England. Multiple logistic regression was used to adjust the estimates for maternal age, ethnicity, deprivation, placenta previa at first birth, inter-birth interval and pregnancy complications. In addition, we conducted a meta-analysis of the reported results in peer-reviewed articles since 1980.

Results: The rate of placenta previa at second birth for women with vaginal first births was 4.4 per 1000 births, compared to 8.7 per 1000 births for women with CS at first birth. After adjustment, CS at first birth remained associated with an increased risk of placenta previa (odds ratio $=1.60 ; 95 \% \mathrm{Cl} 1.44$ to 1.76). In the meta-analysis of 37 previously published studies from 21 countries, the overall pooled random effects odds ratio was $2.20(95 \% \mathrm{Cl}$ 1.96-2.46). Our results from the current study is consistent with those of the meta-analysis as the pooled odds ratio for the six population-based cohort studies that analyzed second births only was 1.51 (95\% Cl 1.39-1.65).

Conclusions: There is an increased risk of placenta previa in the subsequent pregnancy after CS delivery at first birth, but the risk is lower than previously estimated. Given the placenta previa rate in England and the adjusted effect of previous CS, 359 deliveries by CS at first birth would result in one additional case of placenta previa in the next pregnancy.
\end{abstract}

\section{Background}

Placenta previa can have serious adverse consequences for both mother and baby, including an increased risk of maternal and neonatal mortality[1-3], fetal growth restriction and preterm delivery[4], antenatal and intrapartum hemorrhage[5-7], and women may require a blood transfusion[8] or even an emergency hysterectomy. It is a relatively uncommon condition, with an overall incidence in England of 6.3 per 1000 births[9], but incidence rates are higher among women with advanced maternal age, multiple gestation, high parity, or who smoke or use illegal drugs[10]. The risk of

\footnotetext{
* Correspondence: ipek.gurol@lshtm.ac.uk

'Department of Health Services Research and Policy, London School of

Hygiene and Tropical Medicine, London, UK

Full list of author information is available at the end of the article
}

placenta previa is also reported to be higher among women with previous uterine surgery, including cesarean section[11].

In England, cesarean sections constituted 25\% of National Health Service (NHS) deliveries during 2010, and the rates have been rising for both primary and emergency CS[9]. The risk of placenta previa in a pregnancy after a CS delivery has been reported to be between 1.5 and 6 times higher than after a vaginal delivery. A meta-analysis of studies published before 2000 of previous CS as a risk factor for placenta previa found an overall odds ratio of 2.7 [10]. However, the overall odds ratio was lower in studies that had better adjustment for confounders[10]. A recent study from the USA that was not included in the meta-analysis, and which used a population-based cohort of 11 million 
pregnancies, found an adjusted odds ratio of 1.8 for all pregnancies[12] and an adjusted odds ratio of 1.5 for second births only[13].

Evidence about the risk of placenta previa following a previous CS in UK women is limited to results published 25 years ago[14]. We used the Hospital Episode Statistics (HES), an administrative database of all admissions to NHS hospitals in England, to define a population-based cohort and to quantify the association between CS at first birth and the risk of developing placenta previa in the subsequent pregnancy. We also performed a meta-analysis of the reported results in peerreviewed articles since 1980 .

\section{Methods}

\section{The cohort study}

We used the HES dataset for nine financial years from April 2000 to February 2009 for the cohort study. In HES, individual patients are allocated the same identifier for each episode of care[9] and core fields contain patient demographics, clinical information, and hospital administrative data. Diagnostic information is coded using the International Classification of Diseases $10^{\text {th }}$ revision (ICD10) and operative procedures are coded using the UK Office for Population Censuses and Surveys classification, $4^{\text {th }}$ revision (OPCS4). For delivery episodes, the HES dataset also has an additional "maternity tail" which includes parity, birth weight, gestational age, method of delivery, and pregnancy outcome. However, not all records that describe a delivery episode have data entered into this tail.

All women who gave birth to a singleton first and second baby from $1^{\text {st }}$ April 2000 to $28^{\text {th }}$ February 2009 were eligible for inclusion. A delivery was defined as an episode of care that included a relevant OPCS4 code (R17-R25) or ICD10 code (O80-O84) for the mode of delivery, or a maternity tail with a valid date of birth for a baby. Deliveries were coded as a cesarean section by the relevant OPCS4 codes (R17 for primary CS or R18 for emergency CS) or if OPCS4 codes were not available, by the delivery method specified in the maternity tail. If neither of the sets of codes were available $(0.5 \%$ of delivery episodes $)$, vaginal delivery was assumed.

We confined the analysis to NHS trusts (acute hospital organizations) that had a reasonable level of data completeness on parity, defined as having parity information in the maternity tail for more than $50 \%$ of the delivery episodes in at least seven of the nine years covered in the study. NHS trusts were included if the proportion of nulliparous women in that trust was between $25 \%$ and $55 \%$ (which corresponded to the overall rate in England and Wales $\pm 15 \%[15])$ to remove hospitals with poor data quality. Women were allocated to the NHS trusts that existed in February 2009 to take account of previous organizational mergers.

We used the HES patient identifier to trace the second births of those women who had been recorded as nulliparous and who had singleton first births in identified NHS trusts. Diagnostic information for the second birth was taken from the core HES diagnosis fields. Cases of placenta previa were identified by the ICD10 code O44. Pregnancy complications were identified using ICD10 codes O10, O11, O16 for pre-existing hypertension; $\mathrm{O} 13$ for gestational hypertension; O14 and O15 for pre-eclampsia and eclampsia; O24.4 and O24.9 for gestational diabetes; and $\mathrm{O} 40$ for polyhydramnios.

The effect of previous CS delivery on the risk of placenta previa was estimated using unadjusted and adjusted odds ratios. Multiple logistic regression was used to calculate the odds ratios and the risk of placenta previa adjusted for maternal age $(<20,20-29,30-39$, $\geq 40$ ), maternal ethnicity (White, Asian, Black and Other), deprivation, inter-birth interval $(<1,1-2,2-3,3-$ $4,4-5, \geq 5$ years), placenta previa at first birth and indicators for pregnancy complications (i.e., pre-existing hypertension, gestational hypertension including preeclampsia and eclampsia, gestational diabetes and polyhydramnios). Deprivation was measured using the 2004 Index of Multiple Deprivation (IMD) rank of the English Super Output Areas. The IMD combines a range of economic, social and housing indicators into a single deprivation score for each small area in England [16]. Categories were defined by partitioning the ranks of the 32,480 areas into quintiles (0-20th percentiles, 20-40th percentiles, etc.) and labeled 1 (least deprived) to 5 (most deprived). Women were allocated a category based on their region of residence. We calculated the number needed to harm using the adjusted estimates from the logistic regression[17].

We examined whether the effect of CS on placenta previa rates was related to the level of other risk factors, such as whether the effect of CS on the placenta previa risk differed between younger and older women. The significance of an interaction term between previous CS and other risk factors was assessed with the likelihood ratio test. All analyses were done in Stata/SE 10.0.

The study is exempt from IRB and UK NREC approval as it involved analysis of an existing dataset comprising information on delivery episodes for women who cannot be identified directly or through the HES patient numbers linked to them.

\section{Review of literature and meta-analysis}

We searched Pubmed, Embase, Web of Science, Cinahl and the Cochrane Library for the period January 1980 to January 2011 to identify studies that examined the relationship between previous cesarean section and 
placenta previa. The keywords of "placenta previa"/"placenta praevia" and "cesarean"/"caesarean" were searched in MESH headings, titles and abstracts to locate relevant articles. We also checked the references of the selected articles and previous reviews. We only included articles written in English and limited the search to peerreviewed journals.

We selected studies in which placenta previa was diagnosed or recorded at third trimester or during delivery. If two or more relevant articles used the same data source in overlapping years, we selected the study that adjusted the effect size by age or parity, and if there is still replication, the study with the larger sample size.

Estimated log odds ratios and standard errors of log odds ratios were calculated from raw data presented in the included papers. The meta-analysis was performed using a random-effects model, and summarized the degree of consistency across the study results using the $\mathrm{I}^{2}$ measure, the percentage of total variation across studies that is due to heterogeneity rather than chance [18]. Meta-regression was used to assess whether the effect size was associated with date of publication, study design (cohort vs. case-control), source of data (population vs. hospital based), method of diagnosis of placenta previa (confirmed at delivery vs. recorded at hospital or birth registry databases), and whether the results were adjusted for age and parity. We also did a subgroup analysis of population-based cohort studies focusing on the association between first-birth cesarean delivery and second-birth placenta previa and compared the magnitude of this association with the results from our cohort.

\section{Results}

\section{The cohort study}

Between April 2000 and February 2009, there were 4,987,245 singleton delivery episodes in 146 English NHS trusts. It was necessary to exclude 76 NHS trusts due to incomplete parity information. This left $2,484,468$ (49.8\%) singleton delivery episodes in 70 NHS trusts. Of these, 958,882 (38.6\%) women were nulliparous and 399,674 had had a second singleton birth by February 2009. The overall rate of placenta previa for the cohort at first birth was 3.6 and at second birth was 5.3 per 1000 births. The proportion of women who had undergone a CS at first birth was $21.5 \%$. The median birthweight at second birth was 3448 grams (Interquartile range: 3110 -3780 grams).

The rate of placenta previa at second birth was 4.4 per 1000 births for women with vaginal delivery at first birth and 8.7 for women with CS at first birth (unadjusted odds ratio $=1.88$ ). We found that this increased risk of placenta previa persisted after other risk factors were taken into account (adjusted odds ratio $=1.60)($ Table
1). The strongest association between a maternal characteristic and the risk of placenta previa was for women who had placenta previa at first birth (adjusted odds ratio $=4.77)$. Women with advanced maternal age, with polyhydramnios, with very short birth intervals of less than one year, and with birth intervals of more than four years also had higher placenta previa risks. Women with pre-existing hypertension had lower placenta previa risks. Using these estimates, we expect that 359 CS deliveries at first birth would result in one additional case of placenta previa at second birth.

Individual interactions with categories for maternal age, ethnicity, deprivation, maternal risk factors and inter-pregnancy interval did not modify the size of the effect of a previous CS on the risk of placenta previa.

\section{Review of literature and meta-analysis}

We identified 2077 articles of which 74 were of potential relevance to merit a full-text review. 41 articles were selected for inclusion in the review, and an additional eight articles were retrieved from reference lists [8,12,13,19-64]. Among the 49 articles, 12 used overlapping datasets with other studies and were excluded. Study characteristics are presented in Table 2 and the meta-analysis results from the selected 37 studies are given in Figure 1. The overall pooled random effects odds ratio was 2.20 (95\% CI 1.96-2.46). The spread of the odds ratios reported in the individual studies were larger than can be expected by chance alone $\left(\mathrm{I}^{2}=87.6 \%\right)$.

In bi-variate meta-regressions of various study characteristics on the reported odds ratios (Table 3), significantly smaller effect size of previous cesarean section on placenta previa was associated with recent studies $(\mathrm{p}=$ $0.04)$, population-based studies $(\mathrm{p}=0.03)$, and those that adjusted for age and parity $(\mathrm{p}=0.04)$. The odds ratios reported in the individual studies were not associated with type of study design (cohort vs. case-control) and method of diagnosis of placenta previa (data record in database vs. confirmation at delivery). Heterogeneity across studies remained in subgroup analyses by study design, setting and timing of diagnosis of placenta previa. Results from studies that adjusted for age and parity were less heterogeneous $\left(\mathrm{I}^{2}=52.3 \%\right)$ and the variation in the results from studies that analyzed first two births were due to chance alone $\left(\mathrm{I}^{2}=0 \%\right)$.

The pooled random effects odds ratio for the six population-based cohort studies analyzing second births only was 1.51 (95\% CI $\left.1.39-1.65, \mathrm{I}^{2}=0 \%\right)$, comparable to our cohort study.

The pooled odds ratio and association of study characteristics on the odds ratio remained similar after inclusion of the current study in the meta-analysis. The subgroup of studies analyzing first two births had significantly smaller effect sizes $(p=0.04)$. 
Table 1 Maternal characteristics and rate of placenta previa (per 1000 births) in second births

\begin{tabular}{|c|c|c|c|c|}
\hline & Number (\%) of births & Placenta Previa Rate & $\begin{array}{c}\text { Unadjusted OR } \\
(95 \% \mathrm{Cl})^{* *}\end{array}$ & $\begin{array}{c}\text { Adjusted OR } \\
(95 \% \mathrm{Cl})^{* *}\end{array}$ \\
\hline Previous cesarean delivery & & & $\mathrm{p}<0.001$ & $\mathrm{p}<0.001$ \\
\hline Yes & $86055(21.5)$ & 8.7 & $1.88(1.71-2.07)$ & $1.60(1.44-1.76)$ \\
\hline No & $313619(78.5)$ & 4.4 & - & - \\
\hline Previous placenta previa & & & $\mathrm{p}<0.001$ & $\mathrm{p}<0.001$ \\
\hline Yes & $1429(0.4)$ & 43.4 & $7.74(5.80-10.34)$ & $4.77(3.55-6.42)$ \\
\hline No & 398245 (99.6) & 5.2 & - & - \\
\hline Maternal age* & & & $\mathrm{p}<0.001$ & $p<0.001$ \\
\hline$<20$ & $15393(3.9)$ & 1.9 & $0.56(0.38-0.82)$ & $0.58(0.39-0.86)$ \\
\hline $20-29$ & $191151(47.8)$ & 3.6 & - & - \\
\hline 30-39 & $184237(46.1)$ & 7.1 & $2.01(1.82-2.22)$ & $1.83(1.65-2.05)$ \\
\hline$\geq 40$ & $8887(2.2)$ & 13.2 & $3.60(2.90-4.46)$ & $3.01(2.41-3.75)$ \\
\hline Ethnicity* & & & $p=0.053$ & $p=0.387$ \\
\hline White & $275181(80.4)$ & 5.6 & - & - \\
\hline Asian & $42486(12.4)$ & 4.8 & $0.86(0.74-0.99)$ & $1.03(0.89-1.21)$ \\
\hline Black & $12158(3.6)$ & 5.0 & $0.91(0.70-1.17)$ & $0.96(0.74-1.25)$ \\
\hline Other & $12448(3.6)$ & 6.7 & $1.19(0.96-1.50)$ & $1.22(0.97-1.52)$ \\
\hline Deprivation* & & & $p<0.001$ & $p=0.180$ \\
\hline Q1 Most deprived & $122039(30.6)$ & 4.0 & - & - \\
\hline Q2 & $90740(22.8)$ & 5.1 & $1.30(1.14-1.49)$ & $1.10(0.96-1.26)$ \\
\hline Q3 & $85913(21.6)$ & 6.1 & $1.52(1.33-1.73)$ & $1.15(0.99-1.32)$ \\
\hline Q4 Least deprived & $99403(25.0)$ & 6.5 & $1.63(1.44-1.85)$ & $1.16(1.01-1.33)$ \\
\hline Pre-existing hypertension & & & $p=0.080$ & $p=0.026$ \\
\hline Yes & $5730(1.4)$ & 3.5 & $0.69(0.44-1.08)$ & $0.62(0.39-0.98)$ \\
\hline No & $393944(98.6)$ & 5.4 & - & - \\
\hline Gestational hypertension*** & & & $p=0.322$ & $p=0.098$ \\
\hline Yes & $8464(2.1)$ & 5.1 & $0.85(0.60-1.19)$ & $0.76(0.54-1.07)$ \\
\hline No & $391210(97.9)$ & 5.3 & - & - \\
\hline Gestational diabetes & & & $p=0.337$ & $p=0.892$ \\
\hline Yes & $5586(1.4)$ & 5.9 & $1.19(0.84-1.69)$ & $0.98(0.69-1.39)$ \\
\hline No & 394088 (98.6) & 5.3 & - & - \\
\hline Polyhydramnios & & & $p=0.003$ & $p=0.009$ \\
\hline Yes & $1985(0.5)$ & 11.1 & $2.11(1.35-3.28)$ & $1.92(1.23-3.00)$ \\
\hline No & 397689 (99.5) & 5.3 & - & - \\
\hline Inter-birth interval & & & $\mathrm{p}<0.001$ & $\mathrm{p}<0.001$ \\
\hline$<1$ & $7511(1.9)$ & 6.4 & $1.38(1.02-1.87)$ & $2.08(1.53-2.83)$ \\
\hline 1 to 2 & $120803(30.2)$ & 4.8 & $0.92(0.81-1.03)$ & $1.01(0.90-1.14)$ \\
\hline 2 to 3 & 133834 (33.5) & 5.2 & - & - \\
\hline 3 to 4 & $73992(18.5)$ & 5.5 & $1.08(0.95-1.23)$ & $1.08(0.94-1.23)$ \\
\hline 4 to 5 & $35557(8.9)$ & 6.1 & $1.19(1.01-1.40)$ & $1.19(1.01-1.40)$ \\
\hline$\geq 5$ & $27977(7.0)$ & 6.6 & $1.29(1.09-1.53)$ & $1.32(1.11-1.57)$ \\
\hline
\end{tabular}

* Not including missing values (Maternal age $n=6,0.0 \%$; Deprivation $n=1549,0.4 \%$; Ethnicity $n=57401$, 14.6\% of data missing)

** The model was adjusted for all the variables presented in the table. P-values from the likelihood ratio test

*** Gestational hypertension includes pre-eclampsia and eclampsia

\section{Discussion and Conclusions}

Among women in England, cesarean section in the first delivery increased the risk of placenta previa in the subsequent delivery by $60 \%$. There was no evidence that the effect of CS on placenta previa rates varied among different groups of women or by the time between two pregnancies. The risks of placenta previa in the second pregnancy also increased by previous placenta previa, advanced maternal age and with birth intervals of less than one year or more than four years. Women with pre-existing hypertension were less likely to have placenta previa. Our results are consistent with recent studies from other countries which typically found odds ratios ranging from 1.4 to 1.7 . 
Table 2 Characteristics of the studies included in the meta-analysis

\begin{tabular}{|c|c|c|c|c|c|c|c|}
\hline Study ID & Country & $\begin{array}{l}\text { Study } \\
\text { period }\end{array}$ & $\begin{array}{l}\text { Study } \\
\text { design }\end{array}$ & Population & Size & $\begin{array}{l}\text { First two } \\
\text { births }\end{array}$ & Risk adjustment* \\
\hline Singh_1981 & India & 1973-1978 & Cohort & Hospital & 12040 & 0 & - \\
\hline Gorodeski_1985 & Israel & 1972-1983 & Case-control & Hospital & 455 & 0 & - \\
\hline Sauer_1985 & USA & 1981-1984 & Case-control & Hospital & 135 & 0 & - \\
\hline Clark_1985 & USA & 1977-1983 & Cohort & Hospital & 97799 & 0 & - \\
\hline Rose_1986 & England & 1978-1982 & Case-control & Hospital & 160 & 0 & $\mathrm{AP}$ \\
\hline Hemminki_1987 & Sweden & & Cohort & Population & 7337 & 1 & AP; \\
\hline Nielsen_1989 & Sweden & 1978-1987 & Cohort & Hospital & 24644 & 0 & - \\
\hline Williams_1991 & USA & 1977-1980 & Case-control & Hospital & 12420 & 0 & AP; abortion; alcohol and tobacco use; SE \\
\hline Chattopadhyay_1993 & $\begin{array}{l}\text { Saudi } \\
\text { Arabia }\end{array}$ & 1988-1992 & Cohort & Hospital & 41206 & 0 & - \\
\hline Zhang_1993 & USA & $1988-1990$ & Case-control & Population & 6478 & 0 & - \\
\hline Parazzini_1994 & Italy & 1979-1991 & Case-control & Hospital & 203 & 0 & - \\
\hline Makhseed_1994 & Kuwait & 1992-1992 & Cohort & Hospital & 8721 & 0 & - \\
\hline Khouri_1994 & $\begin{array}{l}\text { Saudi } \\
\text { Arabia }\end{array}$ & $1985-1989$ & Cohort & Hospital & 25551 & 0 & - \\
\hline Taylor_1994 & USA & 1984-1987 & Case-control & Population & 1967 & 0 & AP; abortion; tobacco use \\
\hline To_1995 & $\begin{array}{l}\text { Hong } \\
\text { Kong }\end{array}$ & 1984-1993 & Cohort & Hospital & 50485 & 0 & - \\
\hline Monica_1995 & Sweden & 1983-1990 & Case-control & Population & 4676 & 0 & AP; previous previa \\
\hline Hemminki_1996 & Finland & 1987-1993 & Cohort & Population & 10889 & 1 & AP; provider \\
\hline Chelmow_1996 & USA & 1992-1994 & Case-control & Hospital & 128 & 0 & - \\
\hline Takayama_1997 & Japan & 1974-1994 & Case-control & Hospital & 264 & 0 & - \\
\hline Macones_1997 & USA & 1992-1996 & Case-control & Hospital & 120 & 0 & age; abortion; drug and tobacco use \\
\hline Ziadeh_1999 & Jordan & 1995-1996 & Cohort & Hospital & 18651 & 0 & - \\
\hline Hendricks_1999 & Singapore & 1993-1997 & Cohort & Hospital & 16169 & 0 & - \\
\hline Rageth_1999 & Switzerland & 1983-1996 & Cohort & Population & 255453 & 0 & - \\
\hline Archibong_2001 & $\begin{array}{l}\text { Saudi } \\
\text { Arabia }\end{array}$ & $1997-2002$ & Cohort & Hospital & 15191 & 0 & - \\
\hline $\begin{array}{l}\text { Lydon- } \\
\text { Rochelle_2001 }\end{array}$ & USA & 1987-1996 & Cohort & Population & 95630 & 1 & AP \\
\hline Eniola_2002 & Nigeria & & Case-control & Hospital & 272 & 0 & AP; abortion; SE \\
\hline Gilliam_2002 & USA & 1986-1989 & Case-control & Hospital & 1171 & 1 & AP; abortion; tobacco use \\
\hline Tuzovic_2003 & Croatia & 1992-2001 & Case-control & Hospital & 1206 & 0 & - \\
\hline Hossain_2004 & Bangladesh & 2000-2002 & Cohort & Hospital & 2536 & 0 & - \\
\hline Olive_2005 & Australia & 1998-2002 & Cohort & Hospital & 375653 & 0 & - \\
\hline Getahun_2006 & USA & 1989-1997 & Cohort & Population & 156475 & 1 & $\begin{array}{l}\text { AP; abortion; alcohol and tobacco use; prenatal } \\
\text { care; inter pregnancy interval; SE }\end{array}$ \\
\hline Kennare_2007 & Australia & $1998-2003$ & Cohort & Population & 36038 & 1 & AP; abortion \\
\hline Hung_2007 & Taiwan & $1990-2003$ & Cohort & Hospital & 37702 & 0 & - \\
\hline Daltveit_2008 & Norway & 1967-2003 & Cohort & Population & 637497 & 1 & AP; delivery date \\
\hline Rahim_2009 & Pakistan & 2001-2005 & Cohort & Hospital & 20110 & 0 & - \\
\hline Yang_2009 & USA & $1995-2000$ & Cohort & Population & 11026768 & 0 & $\begin{array}{l}\text { AP; abortion; alcohol, tobacco and drug use; } \\
\text { prenatal care; SE }\end{array}$ \\
\hline Rosenberg_2010 & Israel & $1988-2009$ & Cohort & Hospital & 185476 & 0 & AP; abortion; fertility treatment; tobacco use \\
\hline
\end{tabular}

* AP: age and parity; SE: socioeconomic factors 


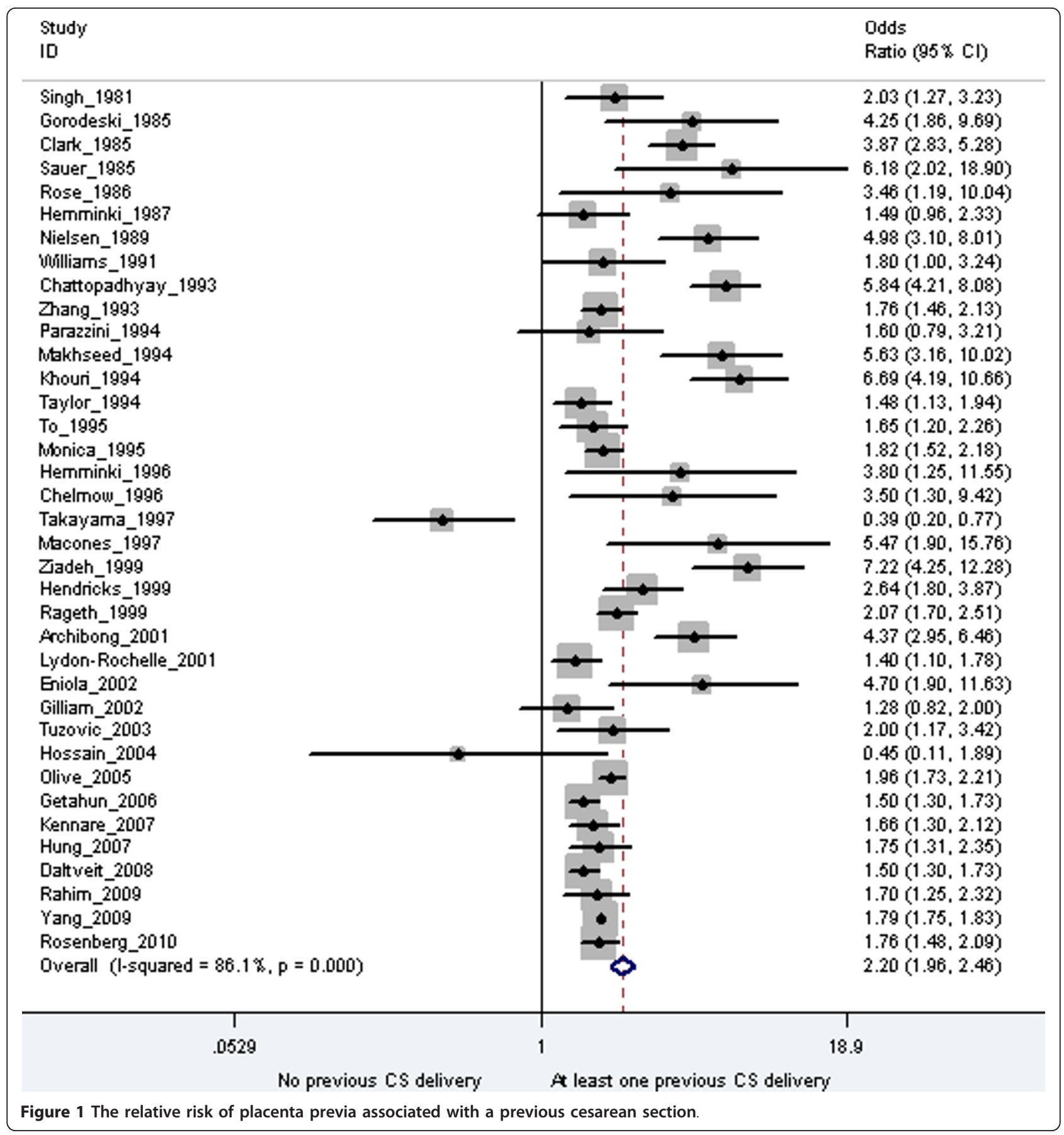

Strengths and limitations of this study

This is the first study of placenta previa risk in England using a large, population-based cohort of nearly 400,000 women with first two births. It included half of all singleton NHS hospital deliveries between April 2000 and February 2009. Due to its comprehensive coverage, the HES database is a valuable resource particularly for studies of relatively uncommon conditions such as placenta previa.
In this study we focused only on the effect of a CS delivery at first birth on a second pregnancy. This has two benefits. First, it corresponds to the information typically required by women and obstetricians. For example, the average achieved family size in the UK is approximately two[65], and so the effect of CS on the second birth is more relevant and accurate than a relative risk based on all pregnancies that may include women with multiple previous CS. Second, estimates 
Table 3 Subgroup analysis of the association between previous cesarean section and placenta previa by study characteristics

\begin{tabular}{|c|c|c|c|c|c|c|c|c|c|c|}
\hline & \multicolumn{5}{|c|}{ Not including current study } & \multicolumn{5}{|c|}{ Including current study } \\
\hline & $\begin{array}{l}\text { Number of } \\
\text { Studies }\end{array}$ & $\begin{array}{l}\text { Random Effects } \\
\text { Pooled OR }\end{array}$ & $\begin{array}{l}\text { Lower } \\
95 \% \mathrm{Cl}\end{array}$ & $\begin{array}{l}\text { Upper } \\
95 \% \mathrm{Cl}\end{array}$ & $\mathrm{I}^{2}$ & $\begin{array}{l}\text { Number of } \\
\text { Studies }\end{array}$ & $\begin{array}{l}\text { Random Effects } \\
\text { Pooled OR }\end{array}$ & $\begin{array}{l}\text { Lower } \\
95 \% \mathrm{Cl}\end{array}$ & $\begin{array}{l}\text { Upper } \\
95 \% \mathrm{Cl}\end{array}$ & $1^{2}$ \\
\hline Overall & 37 & 2.199 & 1.964 & 2.462 & $86.1 \%$ & 38 & 2.155 & 1.941 & 2.395 & $86.0 \%$ \\
\hline \multicolumn{11}{|l|}{ Study design } \\
\hline Cohort studies & 23 & 2.345 & 2.045 & 2.690 & $89.7 \%$ & 24 & 2.284 & 2.014 & 2.591 & $89.5 \%$ \\
\hline $\begin{array}{l}\text { Case-control } \\
\text { studies }\end{array}$ & 14 & 1.933 & 1.517 & 2.464 & $71.0 \%$ & 14 & 1.933 & 1.517 & 2.464 & $71.0 \%$ \\
\hline \multicolumn{11}{|l|}{ Setting } \\
\hline $\begin{array}{l}\text { Population-based } \\
\text { studies }\end{array}$ & 11 & 1.674 & 1.549 & 1.809 & $86.7 \%$ & 12 & 1.664 & 1.553 & 1.785 & $56.0 \%$ \\
\hline $\begin{array}{l}\text { Hospital-based } \\
\text { studies }\end{array}$ & 26 & 2.677 & 2.146 & 3.339 & $86.8 \%$ & 26 & 2.677 & 2.146 & 3.339 & $86.8 \%$ \\
\hline \multicolumn{11}{|l|}{$\begin{array}{l}\text { Timing of PP } \\
\text { diagnosis }\end{array}$} \\
\hline Confirmed at CS & 13 & 2.515 & 1.751 & 3.613 & $88.2 \%$ & 13 & 2.515 & 1.751 & 3.613 & $88.2 \%$ \\
\hline Other & 24 & 1.982 & 1.781 & 2.206 & $80.9 \%$ & 25 & 1.936 & 1.756 & 2.135 & $80.7 \%$ \\
\hline \multicolumn{11}{|l|}{ Inclusion criteria } \\
\hline $\begin{array}{l}\text { Studies analyzing } \\
2^{\text {nd }} \text { births only }\end{array}$ & 7 & 1.504 & 1.383 & 1.635 & $0 \%$ & 8 & 1.540 & 1.442 & 1.645 & $0 \%$ \\
\hline Other & 30 & 2.462 & 2.138 & 2.835 & $87.6 \%$ & 30 & 2.462 & 2.138 & 2.835 & $87.6 \%$ \\
\hline \multicolumn{11}{|l|}{ Risk-adjustment } \\
\hline $\begin{array}{l}\text { Adjusted for age } \\
\text { and parity }\end{array}$ & 14 & 1.648 & 1.515 & 1.792 & $52.3 \%$ & 15 & 1.642 & 1.524 & 1.769 & $54.1 \%$ \\
\hline $\begin{array}{l}\text { Unadjusted } \\
\text { estimates }\end{array}$ & 23 & 2.712 & 2.174 & 3.383 & $87.7 \%$ & 23 & 2.712 & 2.174 & 3.383 & $87.7 \%$ \\
\hline
\end{tabular}

based on all pregnancies will be influenced by the proportions of women in $2^{\text {nd }}, 3^{\text {rd }}, 4^{\text {th }} \ldots$ pregnancies contained in the study sample. Study samples may also differ in the observed sequences of modes of delivery (for example, due to differences in the propensity of local women to opt for trial of labor). Both factors will reduce the comparability of the estimates across studies. We note that, while there is a wide range of reported relative risks, there is consistency in the effect sizes for studies limited to second births.

It is possible that the women with incomplete data in the maternity tail differed from women included in the study in terms of their characteristics and pregnancy risks. However, the distributions of maternal age and mode of delivery were similar in the episodes with good quality data and omitted episodes, which suggests the risk of selection bias is likely to be small.

The coding of the diagnoses and procedures in administrative databases is potentially inaccurate. However, this is unlikely to have had a major effect in our study because previous studies have reported high-levels of agreement in the coding of cesarean section between administrative databases and medical reviews (kappa > 0.98, where stated) [66-68]. Furthermore, cesarean deliveries were defined using the first three characters of the full 4-character OPCS codes, and broader categories rather than specific codes have been shown to be more reliable[69].

Just like other population-based studies, we were not able to confirm the grade and severity of placenta previa $[70,71]$. We were also not able to control for behavioral risk factors, such as maternal smoking and alcohol and drug use, and previous abortions [40,72-74]. However, the effects of these risk factors as reported in the literature are small compared to the effect of prior CS, maternal age and parity[10].

\section{Comparison with other studies}

In the previous meta-analysis of 21 studies, the pooled odds ratios of previous CS as a risk factor for placenta previa was found to be 2.7 (95\% CI: 2.3 to 3.2 ). The same study emphasized that the odds ratios were highly variable by setting, study design, sample size and quality. For well-designed studies, the pooled odds ratio was 1.9 (95\% CI: 1.7 to 2.2)[10].

Since this review, a number of studies have been published. 13 of the 37 studies included in our meta-analysis are post-2000 and cover approximately 12 million women. The pooled odds-ratio of 2.2 (95\% CI: 2.0 to 2.5) from this meta-analysis is less than the previous review, and reflects the fact that studies with recent publication dates found smaller effect sizes. 
Our results for the English cohort are in agreement with other recent, population-based cohorts analyzing second-births only. In the largest population-based cohort study of over 11 million singleton deliveries between 1995 and 2000 in the USA, the adjusted odds ratio of the effect of previous CS on placenta previa at second-birth was 1.5[75]. Other population-based cohort studies published in the last decade reported adjusted odds ratios ranging from 1.4 to 1.7, using Missouri state birth certificates data[26], Washington state Birth Events data[8], South Australian Perinatal Data[37] and Medical Birth Registry of Norway[49]. A population-based study using data from the Swedish Birth Registry found a higher adjusted odds ratio of 1.8 , but this study did not adequately control for risk factors[76].

A few studies have investigated whether the effect of a previous CS on the risk of placenta previa was modified by other risk factors. The Missouri cohort study found that the effect of CS was 70\% higher for women with a second pregnancy within a year after the first delivery [26]. We did not find evidence to support the hypothesis that inter-pregnancy interval influences the size of effect of first birth CS. Our results are consistent with the Washington state cohort study that found the size of effect of CS was not influenced by maternal age at second birth [8].

\section{Implications for policy and practice}

Cesarean section rates are rising worldwide, and an increase in the longer term complications of CS should be anticipated. The presumed short and long term safety of CS is probably one of the factors underlying both the growing rate of CS and the wide variation in CS rates not accounted for by case mix. There is a need for better understanding of the relative risks associated with vaginal and CS births to support decision-making by mothers and clinicians[77].

The Confidential Enquiry into Maternal and Child Health recommends that women with a prior CS should have placental localization in current pregnancy to exclude placenta previa[78]. If placenta previa is diagnosed, there must be further investigation to exclude placenta accreta, a potentially life-threatening condition. In high-income countries, advanced radiological facilities can help to diagnose this serious condition in antenatal care and to plan delivery in a tertiary care unit. However, in low or middle-income countries, placental conditions may be encountered first time at the CS with its serious consequences and it is imperative that senior and experienced doctors are involved in the care of women with placenta previa from the outset.

Our study has demonstrated that, in addition to women with previous CS, women with advanced maternal age, women with birth intervals of less than one year and women who had a previous placenta previa are at a higher risk of developing placenta previa. Nonetheless, our study suggests that the absolute risk remains small. Women who had placenta previa in their previous pregnancy were at the greatest risk of placenta previa in a current pregnancy but less than 5 in 100 of women with a previous placenta previa would be expected to have this complication again. Clinicians should consider and communicate these factors when counseling their patients using appropriate and simplified risk statistics[79]. Our study quantifies this risk and provides data that can be used to reassure women, attending for pre-conception counseling clinics or antenatal clinics as well as in pre-operative consent discussions for women undergoing CS.

\section{Acknowledgements}

We thank the Department of Health for providing the Hospital episode statistics data used in this study. IGU is supported by the Royal College of Obstetricians and Gynaecologists.

\section{Author details}

'Department of Health Services Research and Policy, London School of Hygiene and Tropical Medicine, London, UK. ${ }^{2}$ Office for Research and Clinical Audit, Lindsay Stewart R\&D Centre, Royal College of Obstetricians and Gynaecologists, London, UK. ${ }^{3}$ Maternal and Fetal Health Research Centre, Manchester Academic Health Sciences Centre, Manchester, UK. ${ }^{4}$ Department of Obstetrics and Gynaecology, Cambridge University, Cambridge, UK.

\section{Authors' contributions}

All authors have fulfilled all conditions required for authorship. IGU, GCS, LCE, DC, JVdM and TAM designed the study. IGU analyzed the data supported by DC and JvdM. IGU wrote the first draft. All authors contributed to the interpretation of the results, revised further drafts, and approved the final manuscript.

\section{Competing interests}

The authors declare that they have no competing interests.

Received: 8 June 2011 Accepted: 21 November 2011

Published: 21 November 2011

\section{References}

1. Salihu HM, Li Q, Rouse DJ, Alexander GR: Placenta previa: Neonatal death after live births in the United States. Am J Obstet Gynecol 2003, 188(5):1305-1309.

2. Ananth CV, Smulian JC, Vintzileos AM: The effect of placenta previa on neonatal mortality: a population-based study in the United States, 1989 through 1997. Am J Obstet Gynecol 2003, 188(5):1299-1304.

3. Iyasu S, Saftlas AK, Rowley DL, Koonin LM, Lawson HW, Atrash HK: The Epidemiology of Placenta-Previa in the United-States, 1979 Through 1987. Am J Obstet Gynecol 1993, 168(5):1424-1429.

4. Ananth CV, Demissie K, Smulian JC, Vintzileos AM: Relationship among placenta previa, fetal growth restriction, and preterm delivery: A population based study. Obstet Gynecol 2001, 98(2):299-306.

5. Brace $V$, Kernaghan D, Penney G: Learning from adverse clinical outcomes: major obstetric haemorrhage in Scotland, 2003-05. BJOG 2007, 114(11):1388-1396.

6. Crane JMG, Van den Hof MC, Dodds L, Armson BA, Liston R: Maternal complications with placenta previa. Am J Perinatol 2000, 17(2):101-105.

7. Bhide A, Prefumo F, Moore J, Hollis B, Thilaganathan B: Placental edge to internal os distance in the late third trimester and mode of delivery in placenta praevia. BJOG 2003, 110(9):860-864. 
8. Lydon-Rochelle M, Holt VL, Easterling TR, Martin DP: First-birth cesarean and placental abruption or previa at second birth. Obstet Gynecol 2001, 97(5):765-769

9. HESOnline. 2011 [http://www.hesonline.nhs.uk/.

10. Faiz AS, Ananth CV: Etiology and risk factors for placenta previa: an overview and meta-analysis of observational studies. J Matern Fetal Neonatal Med 2003, 13(3):175-190.

11. Ananth CV, Smulian JC, Vintzileos AM: The association of placenta previa with history of cesarean delivery and abortion: A metaanalysis. Am J Obstet Gynecol 1997, 177(5):1071-1078.

12. Yang Q, Wen SW, Phillips K, Oppenheimer L, Black D, Walker MC: Comparison of maternal risk factors between placental abruption and placenta previa. American Journal of Perinatology 2009, 26(4):279-286.

13. Yang Q, Wen SW, Oppenheimer L, Chen XK, Black D, Gao J, Walker MC: Association of caesarean delivery for first birth with placenta praevia and placental abruption in second pregnancy. BJOG: An International Journal of Obstetrics and Gynaecology 2007, 114(5):609-613.

14. Rose GL, Chapman MG: Aetiological factors in placenta praevia-a case controlled study. Br J Obstet Gynaecol 1986, 93(6):586-588.

15. ONS: Birth statistics: Births and patterns of family building England and Wales (FM1) FM1 No. 36. Table 1.9 Components of total fertility rates1: occurrence within/outside England and Wales marriage, birth order and age of mother, 1997-2007. 2007.

16. Office of the Deputy Prime Minister. The English indices of deprivation 2004: summary (revised). [http://www.communities.gov.uk/documents/ communities/pdf/131206.pdf]

17. Bender R, Kuss O, Hildebrandt M, Gehrmann U: Estimating adjusted NNT measures in logistic regression analysis. Stat Med 2007, 26(30):5586-5595.

18. Higgins JP, Thompson SG: Quantifying heterogeneity in a meta-analysis. Stat Med 2002, 21(11):1539-1558.

19. Abu-Heija AT, El-Jallad F, Ziadeh S: Placenta previa: Effect of age, gravidity, parity and previous caesarean section. Gynecologic and Obstetric Investigation 1999, 47(1):6-8.

20. Archibong El, Ahmed ESM: Risk factors, maternal and neonatal outcome in major placenta previa: A prospective study. Annals of Saudi Medicine 2001, 21(3-4):245-247.

21. Chattopadhyay SK, Kharif H, Sherbeeni MM: Placenta praevia and accreta after previous caesarean section. European Journal of Obstetrics Gynecology and Reproductive Biology 1993, 52(3):151-156.

22. Chelmow D, Andrew DE, Baker ER: Maternal cigarette smoking and placenta previa. Obstetrics and Gynecology 1996, 87(5 I):703-706.

23. Clark SL, Koonings PP, Phelan JP: Placenta previa/accreta and prior cesarean section. Obstetrics and Gynecology 1985, 66(1):89-92.

24. Daltveit AK, Tollanes MC, Pihlstrom R, Irgens LM: Cesarean delivery and subsequent pregnancies. Obstetrics and Gynecology 2008, 111(6):1327-1334.

25. Eniola $\mathrm{AO}$, Bako $\mathrm{AU}$, Selo-Ojeme DO: Risk factors for placenta praevia in southern Nigeria. East Afr Med J 2002, 79(10):535-538.

26. Getahun D, Oyelese Y, Salihu HM, Ananth CV: Previous cesarean delivery and risks of placenta previa and placental abruption. Obstet Gynecol 2006, 107(4):771-778.

27. Gilliam M, Rosenberg D, Davis F: The likelihood of placenta previa with greater number of cesarean deliveries and higher parity. Obstetrics and Gynecology 2002, 99(6):976-980

28. Gorodeski IG, Bahari CM: The effect of placenta previa localization upon maternal and fetal-neonatal outcome. J Perinat Med 1987, 15(2):169-177.

29. Gorodeski IG, Neri A, Bahary CM: Placenta previa - The identification of low- and high-risk subgroups. European Journal of Obstetrics Gynecology and Reproductive Biology 1985, 20(3):133-143.

30. Handler AS, Mason ED, Rosenberg DL, Davis FG: The relationship between exposure during pregnancy to cigarette smoking and cocaine use and placenta previa. Am J Obstet Gynecol 1994, 170(3):884-889.

31. Hemminki E: Pregnancy and birth after cesarean section: a survey based on the Swedish birth register. Birth 1987, 14(1):12-17.

32. Hemminki E, Merilainen J: Long-term effects of cesarean sections: Ectopic pregnancies and placental problems. American Journal of Obstetrics and Gynecology 1996, 174(5):1569-1574.

33. Hendricks MS, Chow YH, Bhagavath B, Singh K: Previous cesarean section and abortion as risk factors for developing placenta previa. Journal of Obstetrics and Gynaecology Research 1999, 25(2):137-142.
34. Hershkowitz R, Fraser D, Mazor M, Leiberman JR: One or multiple previous cesarean sections are associated with similar increased frequency of placenta previa. European Journal of Obstetrics Gynecology and Reproductive Biology 1995, 62(2):185-188

35. Hossain GA, Islam SM, Mahmood S, Chakraborty RK, Akhter N, Sultana S: Placenta previa and it's relation with maternal age, gravidity and cesarean section. Mymensingh Med J 2004, 13(2):143-148.

36. Hung TH, Hsieh CC, Hsu JJ, Chiu TH, Lo LM, Hsieh TT: Risk factors for placenta previa in an Asian population. Int I Gynaecol Obstet 2007, 97(1):26-30.

37. Kennare R, Tucker G, Heard A, Chan A: Risks of adverse outcomes in the next birth after a first cesarean delivery. Obstetrics and Gynecology 2007, 109(2 PART 1):270-276.

38. Khouri JA, Sultan MG: Previous caesarean section and the rising incidence of placenta praevia and placenta accreta. Journal of Obstetrics and Gynaecology 1994, 14(1):14-16.

39. Kramer MD, Taylor V, Hickok DE, Daling JR, Vaughan TL, Hollenbach KA: Maternal smoking and placenta previa. Epidemiology 1991, 2(3):221-223.

40. Macones GA, Sehdev HM, Parry S, Morgan MA, Berlin JA: The association between maternal cocaine use and placenta previa. Am J Obstet Gynecol 1997, 177(5):1097-1100

41. Makhseed M, El-Tomi N, Moussa M: A retrospective analysis of pathological placental implantation - Site and penetration. International Journal of Gynecology and Obstetrics 1994, 47(2):127-134.

42. McMahon MJ, Li R, Schenck AP, Olshan AF, Royce RA: Previous cesarean birth: A risk factor for placenta previa? Journal of Reproductive Medicine for the Obstetrician and Gynecologist 1997, 42(7):409-412.

43. Monica G, Lilja C: Placenta previa, maternal smoking and recurrence risk. Acta Obstet Gynecol Scand 1995, 74(5):341-345.

44. Nielsen TF, Hagberg H, Ljungblad U: Placenta previa and antepartum hemorrhage after previous cesarean section. Gynecologic and Obstetric Investigation 1989, 27(2):88-90.

45. Olive EC, Roberts CL, Algert CS, Morris JM: Placenta praevia: Maternal morbidity and place of birth. Australian and New Zealand Journal of Obstetrics and Gynaecology 2005, 45(6):499-504

46. Parazzini F, Dindelli M, Luchini L, La Rosa M, Potenza MT, Frigerio L, Ferrari A: Risk factors for placenta praevia. Placenta 1994, 15(3):321-326

47. Rageth JC, Juzi C, Grossenbacher H: Delivery after previous cesarean: A risk evaluation. Obstetrics and Gynecology 1999, 93(3):332-337.

48. Rahim R, Shafqat T, Fayyaz S: An analysis of association of scarred uterus with placenta praevia and morbid adherence of placenta. Journal of Medical Sciences 2009, 17(2):60-63.

49. Rasmussen S, Albrechtsen S, Dalaker K: Obstetric history and the risk of placenta previa. Acta Obstetricia et Gynecologica Scandinavica 2000, 79(6):502-507.

50. Rose GL, Chapman MG: Aetiological factors in placenta praevia - a case controlled study. British Journal of Obstetrics and Gynaecology 1986, 93(6):586-588

51. Sauer M, Parsons M, Sampson M: Placenta previa: An analysis of three years experience. American Journal of Perinatology 1985, 2(1):39-42.

52. Sheiner E, Shoham-Vardi I, Hallak M, Hershkowitz R, Katz M, Mazor M: Placenta previa: Obstetric risk factors and pregnancy outcome. Journal of Maternal Fetal Medicine 2001, 10(6):414-419.

53. Singh PM, Rodrigues C, Gupta AN: Placenta previa and previous cesarean section. Acta Obstetricia et Gynecologica Scandinavica 1981, 60(4):367-368.

54. Takayama T, Minakami H, Koike T, Watanabe T, Sato I: Risks associated with cesarean sections in women with placenta previa. Journal of Obstetrics and Gynaecology Research 1997, 23(4):375-379.

55. Taylor VM, Kramer MD, Vaughan TL, Peacock S: Placental previa in relation to induced and spontaneous abortion: a population-based study. Obstet Gynecol 1993, 82(1):88-91.

56. Taylor VM, Kramer MD, Vaughan TL, Peacock S: Placenta previa and prior cesarean delivery: How strong is the association? Obstetrics and Gynecology 1994, 84(1):55-57.

57. Taylor VM, Peacock S, Kramer MD, Vaughan TL: Increased risk of placenta previa among women of Asian origin. Obstetrics and Gynecology 1995, 86(5):805-808.

58. To WWK, Leung WC: Placenta previa and previous cesarean section. International Journal of Gynecology and Obstetrics 1995, 51(1):25-31. 
59. Tuzovic L, Djelmis J, Ilijic M: Obstetric Risk Factors Associated with Placenta Previa Development: Case-Control Study. Croatian Medical Journal 2003, 44(6):728-733.

60. Williams MA, Mittendorf R, Lieberman E, Monson RR, Schoenbaum SC, Genest DR: Cigarette smoking during pregnancy in relation to placenta previa. Am J Obstet Gynecol 1991, 165(1):28-32.

61. Zhang J, Fried DB: Relationship of maternal smoking during pregnancy to placenta previa. American Journal of Preventive Medicine 1992, 8(5):278-282

62. Zhang J, Savitz DA: Maternal age and placenta previa: A populationbased, case-control study. American Journal of Obstetrics and Gynecology 1993, 168(2):641-645.

63. Ziadeh SM, Abu-Heija AT, El-Jallad MF: Placental praevia and accreta: An analysis of two-years' experience. Journal of Obstetrics and Gynaecology 1999, 19(6):584-586.

64. Rosenberg T, Pariente G, Sergienko R, Wiznitzer A, Sheiner E: Critical analysis of risk factors and outcome of placenta previa. Arch Gynecol Obstet 2010.

65. Jefferies J: Fertility assumptions for the 2006-based national population projections. Popul Trends 2008, 131:19-27.

66. Roberts $\mathrm{CL}$, Bell JC, Ford JB, Morris JM: Monitoring the quality of maternity care: how well are labour and delivery events reported in population health data? Paediatr Perinat Epidemiol 2009, 23(2):144-152.

67. Lydon-Rochelle M, Holt VL, Easterling TR, Martin DP: Risk of uterine rupture during labor among women with a prior cesarean delivery. N Engl J Med 2001, 345(1):3-8.

68. Yasmeen S, Romano PS, Schembri ME, Keyzer JM, Gilbert WM: Accuracy of obstetric diagnoses and procedures in hospital discharge data. Am J Obstet Gynecol 2006, 194(4):992-1001.

69. Dixon J, Sanderson C, Elliott P, Walls P, Jones J, Petticrew M: Assessment of the reproducibility of clinical coding in routinely collected hospital activity data: a study in two hospitals. J Public Health Med 1998, 20(1):63-69.

70. Dola CP, Garite TJ, Dowling DD, Friend D, Ahdoot D, Asrat A: Placenta previa: Does its type affect pregnancy outcome? Am J Perinatol 2003, 20(7):353-360.

71. Tuzovic L: Complete versus incomplete placenta previa and obstetric outcome. Int J Gynecol Obstet 2006, 93(2):110-117.

72. Ananth CV, Savitz DA, Luther ER: Maternal cigarette smoking as a risk factor for placental abruption, placenta previa, and uterine bleeding in pregnancy. Am J Epidemiol 1996, 144(9):881-889.

73. Williams MA, Mittendorf R, Lieberman E, Monson RR, Schoenbaum SC, Genest DR: Cigarette-Smoking During Pregnancy in Relation to Placenta Previa. Am J Obstet Gynecol 1991, 165(1):28-32.

74. Handler AS, Mason ED, Rosenberg DL, Davis FG: The Relationship Between Exposure During Pregnancy to Cigarette-Smoking and Cocaine Use and Placenta-Previa. Am J Obstet Gynecol 1994, 170(3):884-889.

75. Yang Q, Wen S, Oppenheimer L, Chen X, Black D, Gao J, Walker M: Association of caesarean delivery for first birth with placenta praevia and placental abruption in second pregnancy. BJOG 2007, 114(5):609-613.

76. Monica G, Lilja C: Placenta Previa, Maternal Smoking and Recurrence Risk. Acta Obstet Gynecol Scand 1995, 74(5):341-345.

77. Caesarean Sections. London: The Parliamentary Office of Science and Technology; 2002.

78. Lewis G, (ed): The Confidential Enquiry into Maternal and Child Health (CEMACH). Saving Mothers' Lives: reviewing maternal deaths to make motherhood safer - 2003-2005. The Seventh Report on Confidential Enquiries into Maternal Deaths in the United Kingdom. London: CEMACH; 2007.

79. Spiegelhalter DJ: Understanding uncertainty. Ann Fam Med 2008, 6(3):196-197.

Pre-publication history

The pre-publication history for this paper can be accessed here: http://www.biomedcentral.com/1471-2393/11/95/prepub

doi:10.1186/1471-2393-11-95

Cite this article as: Gurol-Urganci et al: Risk of placenta previa in second birth after first birth cesarean section: a population-based study and meta-analysis. BMC Pregnancy and Childbirth 2011 11:95.

\section{Submit your next manuscript to BioMed Central and take full advantage of:}

- Convenient online submission

- Thorough peer review

- No space constraints or color figure charges

- Immediate publication on acceptance

- Inclusion in PubMed, CAS, Scopus and Google Scholar

- Research which is freely available for redistribution

Submit your manuscript at www.biomedcentral.com/submit
Biomed Central 